\title{
Effects of oxygen administration, bicarbonate infusions, and brief hyperventilation on patients with pulmonary vascular obstructive disease
}

\author{
GEOFFREY MORRISON ${ }^{1}$ AND FERGUS MACARTNEY 2 \\ From the Department of Paediatric Cardiology, Killingbeck Hospital, Leeds
}

SUMMARY In an attempt to clarify further the mechanisms underlying labile rise in pulmonary vascular resistance, the effects of administering high oxygen concentrations, brief voluntary hyperventilation, and correction of acidosis were studied in 16 patients in whom congenital heart disease was associated with pulmonary vascular disease. On breathing 100 per cent oxygen there was a significant fall in pulmonary vascular resistance from $21.8 \pm 4.6$ to $12.9 \pm 3.6$ units $/ \mathrm{m}^{2}(\mathrm{P}<0.001)$, with a rise in pulmonary blood flow from $4.4 \pm 0.6$ to $8.8 \pm 2.01 / \mathrm{min}$ per $\mathrm{m}^{2}(\mathrm{P}<0.025)$ and a fall in pulmonary artery pressure from $67.8 \pm 2.8$ to $61.8 \pm 4.0 \mathrm{mmHg}(\mathrm{P}<0.025)$. The changes occurring on sodium bicarbonate administration in 6 patients did not reach levels of significance, but the size of each individual response was closely correlated with the response to oxygen administration. No significant changes occurred either on voluntary hyperventilation or, in the systemic circulation, with any intervention. However, systemic vascular resistance was positively correlated with pulmonary vascular resistance $(P<0.01)$. As a result of this, though age was correlated positively with both pulmonary artery mean pressure $(P<0.025)$ and vascular resistance $(P<0.025)$, it was not correlated with the ratio of pulmonary to systemic resistance. Since pulmonary vascular disease is progressive, these results cast some doubt on the validity of resistance ratio as a measure of its severity.

Patients with congenital heart disease, particularly when this involves communications between the pulmonary and systemic circulations at ventricular or great arterial level, or concordant (complete) transposition of the great arteries, are at risk of developing pulmonary vascular obstructive disease. This in turn is a major determinant of both immediate and late surgical mortality for correction of the defect (Blount and Woodwark, 1960; Goodwin, 1961 ; Kirklin, 1965; Cartmill et al., 1966; Mair et al., 1974, 1976). The degree of pulmonary vascular obstructive disease can be assessed directly before attempted correction by lung biopsy (Heath et al., 1958b), though this has distinct limitations (Adams et al., 1957; Wagenvoort et al., 1967). A promising, but as yet untested, new technique is inhalation and injection of radioactive nitrogen $\left({ }^{13} \mathrm{~N}\right)$ (McKenzie

\footnotetext{
${ }^{1}$ Present address: Department of Cardiology, Hull Royal Infirmary, Anlaby Road, Hull.

2Present address: The Thoracic Unit, The Hospital for
} Sick Children, Great Ormond Street, London WGIN 3JH.

Received for publication 29 June 1978 et al., 1977). However, the most widely used and tested method is that of assessing pulmonary vascular resistance (or derivatives thereof) during cardiac catheterisation (Adams et al., 1957; Blount and Woodwark, 1960; Goodwin, 1961; Kirklin and DuShane, 1963; Hallman et al., 1964; Kirklin, 1965; Cartmill et al., 1966; Kimball and McIlroy, 1966; Reeve et al., 1966; Hallidie-Smith, 1968; Gotsman et al., 1969; Mair et al., 1974, 1976). A major limitation of this method is that the sedation required to catheterise children itself affects pulmonary vascular resistance (Auld et al., 1963), and may thereby cause pulmonary vascular disease to appear far more severe when assessed by cardiac catheterisation than when judged by clinical examination in the unsedated patient (HallidieSmith et al., 1969). Apart from the direct effects of the drug used for sedation, the most likely causes of an artefactual rise in pulmonary vascular resistance during catheterisation are pulmonary venous hypoxia (caused either by hypoventilation or by atelectasis) and acidaemia. Accordingly we set out to study prospectively the effects of (a) administra- 
tion of high oxygen concentrations, (b) voluntary hyperventilation, and (c) sodium bicarbonate administration on the haemodynamics of patients with pulmonary vascular obstructive disease.

\section{Methods}

The subjects were patients with congenital heart disease in whom the pulmonary vascular resistance was known to be, or strongly suspected to be, raised to levels which might increase the risks and morbidity of surgery or even make surgical intervention prohibited. Patients with obstruction of any type of pulmonary venous return were excluded.

All patients were studied in the fasting state, lightly sedated after being premedicated either with $0.025 \mathrm{ml} / \mathrm{kg}$ of a mixture containing phenoperidine $0.025 \mathrm{mg} / \mathrm{ml}$ and dehydrobenzperidol $2.5 \mathrm{mg} / \mathrm{ml}$, or with $0.1 \mathrm{ml} / \mathrm{kg}$ of a mixture containing pethidine $25 \mathrm{mg} / \mathrm{ml}$, promethazine hydrochloride $6.25 \mathrm{mg} / \mathrm{ml}$, and chlorpromazine 6.25 $\mathrm{mg} / \mathrm{ml}$ (maximal dose $3 \mathrm{ml}$ ). Cardiac catheterisation was performed under local anaesthetic (lignocaine $\mathrm{HCl} 1 \%$ ). Whenever practicable separate cardiac catheters were passed to the main pulmonary artery (both branches in the presence of a persistent ductus arteriosus), the right atrium (also for superior and inferior vena cava blood sampling), left atrium (and one or more pulmonary veins), and a systemic artery. In a few cases, rapid sequential sampling from all these sites was used. Thus, blood sampling for oxygen saturation and pressure recordings were performed simultaneously, or nearly so, together with the measurement of oxygen consumption by the flow-through method (Kappagoda et al., 1973).

Haemodynamic data were first obtained at rest, breathing room air normally. In 6 subjects significant metabolic acidosis, as indicated by the nonrespiratory $p \mathrm{H}<7.31$ (Kappagoda et al., 1970, 1972), was present and measurement of all haemodynamic data was repeated, including measurement of oxygen consumption, after this acidosis had been corrected. This was done by giving 8.4 per cent $\mathrm{w} / \mathrm{v}$ sodium bicarbonate at a constant rate of $2 \mathrm{mmol} / \mathrm{min}$, by infusion pump, until the acidosis, as measured in repeated blood samples, was corrected.

Four subjects were then asked to hyperventilate for one minute, after which time all haemodynamic measurements were repeated, including measurement of the oxygen consumption. Most children found voluntary hyperventilation impossible.

Finally 100 per cent oxygen was administered by close-fitting face mask for 10 minutes to all subjects and haemodynamic measurements were repeated.
Oxygen consumption was not remeasured during oxygen administration but was assumed to have remained unchanged (Barratt-Boyes and Wood, 1958).

The pulmonary and systemic flows were calculated using the Fick method. In the presence of a left-to-right shunt mixed venous (MV) oxygen saturation was obtained from the superior and inferior vena cava (SVC and IVC) saturations (Flamm et al., 1969; Miller et al., 1974):

$$
\mathrm{MV}=\frac{(3 \times \mathrm{SVC})+(1 \times \mathrm{IVC})}{4}
$$

In the 3 patients with associated persistent ductus arteriosus and 2 patients with persistent truncus the mixed pulmonary arterial sample was taken as the mean of both pulmonary arteries. Arterial blood gases were taken from each site, and dissolved oxygen in the plasma was calculated as $0.3 \mathrm{ml} / 100 \mathrm{ml}$ per $100 \mathrm{mmHg}$ (Slonim et al., 1967).

In all cases the pulmonary venous blood was obtained directly from the left atrium or pulmonary veins, if necessary by retrograde left atrial catheterisation (Morrison et al., 1977). No assumptions were, therefore, made about the pulmonary venous oxygen saturation or the mean left atrial pressure. Similarly no assumptions were made for oxygen consumption. Pulmonary and systemic resistances were obtained from the pressure gradients and flows across the respective vascular beds.

In order to determine whether there were specific disturbances in systemic vascular resistance related to pulmonary vascular disease, the actual values of systemic vascular resistance were compared with those predicted from a study of 150 unselected patients with congenital heart disease (Morrison and Macartney, 1978). The factors taken into account in making this prediction were premedication, body size, haematocrit, and systemic arterial oxygen saturation.

Comparisons of haemodynamic data under varying ambient conditions were made using the paired Student's $\mathrm{t}$ test. Correlations were investigated by linear regression analysis.

\section{Results}

Out of 1300 cardiac catheterisations performed during the past 5 years investigation of the lability of raised pulmonary resistance was carried out in 16 subjects $(1 \cdot 2 \%)$. The median age of subjects was 8.9 years (range $0.7-37$ years) and the median weight was $30.6 \mathrm{~kg}$ (range 5.6 to $42 \mathrm{~kg}$ ). The mean haematocrit was 41.2 per cent (range 34 to $60 \%$ ), and the mean systemic oxygen saturation breathing 
Table Anatomical diagnosis and outcome in patients investigated

\begin{tabular}{|c|c|c|c|c|}
\hline \multirow[t]{2}{*}{ Case no. } & \multirow[t]{2}{*}{ Basic diagnosis } & \multicolumn{2}{|c|}{$\begin{array}{l}\text { Pulmonary vascular resistance } \\
\left(\text { units } / m^{2}\right)\end{array}$} & \multirow[t]{2}{*}{ Outcome } \\
\hline & & Air & $O$ & \\
\hline $\begin{array}{l}1 \\
2 \\
3 \\
4\end{array}$ & $\begin{array}{l}\text { Double outlet right ventricle } \\
\text { Ligated persistent ductus arteriosus } \\
\text { Ventricular septal defect } \\
\text { Ventricular septal defect; persistent ductus } \\
\text { arteriosus }\end{array}$ & $\begin{array}{l}38 \\
23 \\
8 \cdot 2 \\
13\end{array}$ & $\begin{array}{l}22 \\
14 \\
8 \cdot 3 \\
4 \cdot 2\end{array}$ & $\begin{array}{l}\text { Died after } 33 \text { months } \\
\text { Alive after } 28 \text { months } \\
\text { Alive after } 32 \text { months } \\
\text { Alive after } 63 \text { months }\end{array}$ \\
\hline 5 & $\begin{array}{l}\text { Concordant transposition of great arteries; } \\
\text { ventricular septal defect }\end{array}$ & $8 \cdot 9$ & $3 \cdot 6$ & Died postoperatively \\
\hline $\begin{array}{l}6 \\
7\end{array}$ & $\begin{array}{l}\text { Persistent truncus arteriosus } \\
\text { Ventricular septal defect; persistent ductus } \\
\text { arteriosus }\end{array}$ & $\begin{array}{l}71 \\
11.5\end{array}$ & $\stackrel{55}{6.6}$ & $\begin{array}{l}\text { Died after } 1 \text { month } \\
\text { Alive after } 40 \text { months }\end{array}$ \\
\hline 8 & $\begin{array}{l}\text { Ventricular septal defect; persistent ductus } \\
\text { arteriosus }\end{array}$ & 14 & $2 \cdot 7$ & Alive after $\mathbf{4 5}$ months \\
\hline $\begin{array}{r}9 \\
10 \\
11 \\
12\end{array}$ & $\begin{array}{l}\text { Ventricular septal defect } \\
\text { Common atrioventricular orifice } \\
\text { Common atrioventricular orifice } \\
\text { Concordant transposition of great arteries; } \\
\text { ventricular septal defect }\end{array}$ & $\begin{array}{c}15 \\
22 \\
46 \\
9 \cdot 5\end{array}$ & $\begin{array}{c}7 \cdot 4 \\
8 \cdot 8 \\
23 \\
5 \cdot 0\end{array}$ & $\begin{array}{l}\text { Alive after } 53 \text { months } \\
\text { Alive after } 49 \text { months } \\
\text { Alive after } 48 \text { months } \\
\text { Died postoperatively }\end{array}$ \\
\hline $\begin{array}{l}13 \\
14\end{array}$ & $\begin{array}{l}\text { Persistent truncus arteriosus } \\
\text { Ventricular septal defect }\end{array}$ & $\begin{array}{ll}12 \\
7 \cdot 0\end{array}$ & $\begin{array}{l}3.9 \\
5.6\end{array}$ & $\begin{array}{l}\text { Died } 1 \text { month postoperatively } \\
\text { Surgical correction; alive after } \\
55 \text { months* }\end{array}$ \\
\hline $\begin{array}{l}15 \\
16\end{array}$ & $\begin{array}{l}\text { Common atrioventricular orifice } \\
\text { Primitive ventricle }\end{array}$ & 44 & 35 & $\begin{array}{l}\text { Died postoperatively* } \\
\text { Alive after } 59 \text { months }\end{array}$ \\
\hline
\end{tabular}

*Pulmonary artery mean pressure fell to 50 per cent of systemic mean pressure.

room air was 79.9 per cent (range 56 to $97 \%$ ). The basic diagnoses of these 16 cases are shown in the Table.

(I) CONTROL HAEMODYNAMIC DATA

Age had a significant positive correlation with mean pulmonary artery pressure $(P<0.025)$ and a negative correlation with pulmonary blood flow $(P<0.01)$. Both these factors are involved in the calculation of pulmonary vascular resistance and there was a significant positive correlation of pulmonary vascular resistance with age $(P<0.01)$

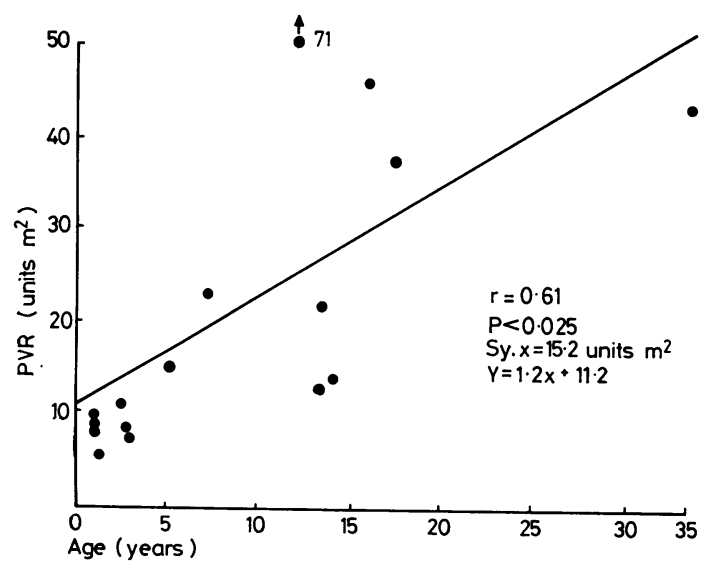

Fig. 1 The relation of pulmonary vascular resistance to age.
(Fig. 1). Pulmonary vascular resistance (PVR) had a significant positive correlation with systemic vascular resistance $(S V R)(P<0.01)$ (Fig. 2). There was no significant correlation between age and the ratio PVR/SVR (Fig. 3). Nor was there any correlation between mean left atrial pressure and total pulmonary blood flow in $1 / \min$ per $\mathrm{m}^{2}$. When information on premedication, body size, haematocrit, and systemic oxygen saturation was fed into a previously derived equation (Morrison and Macartney, 1978) predictive of absolute systemic vascular resistance, the absolute measured value

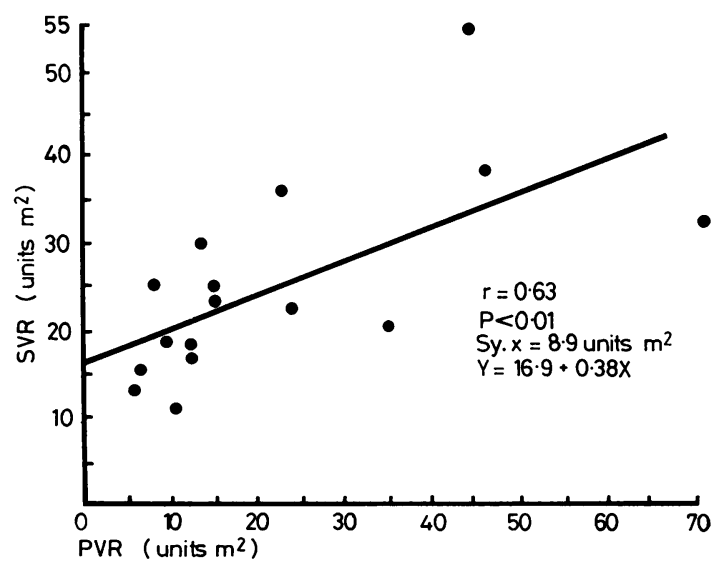

Fig. 2 The relation between systemic and pulmonary vascular resistance. 


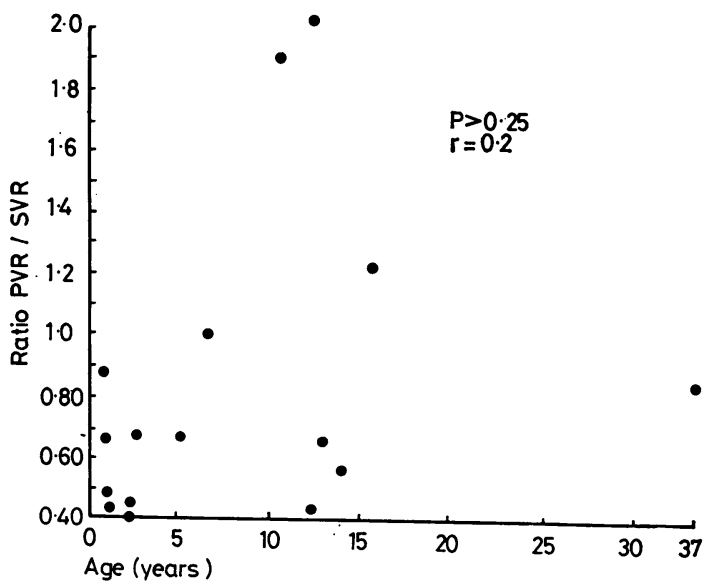

Fig. 3 The relation between the vascular resistance ratio and age.

of $32 \cdot 7 \pm 2 \cdot 0$ units $( \pm$ SEM) was slightly lower than the predicted value of $34.5 \pm 2.4$ units, but this difference was not statistically significant.

(II) EFFECTS OF BREATHING 100 PER CENT OXYGEN

On breathing 100 per cent oxygen there was a fall in pulmonary artery mean pressure in all except 3 out of the 16 patients, and the overall decrease was highly significant $(P<0.025)$. Those 3 patients who had a rise in mean pulmonary artery pressure were among the 5 with the highest control pressures (Fig. 4). There was a rise in pulmonary artery blood flow in all of the 16 patients $(P<0.025)$ (Fig. 5). With a fall in pressure and an increase in flow, the
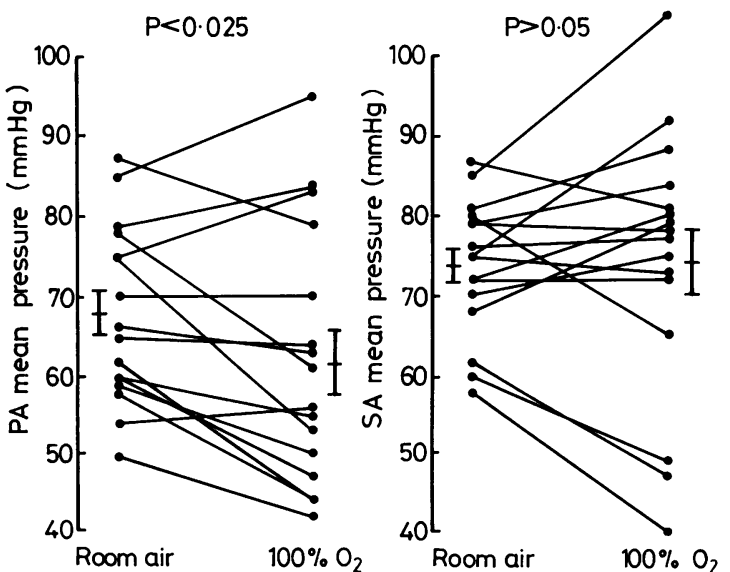

Fig. 4 The response of the mean pulmonary and systemic arterial pressures to oxygen. The bars show means and their standard errors.
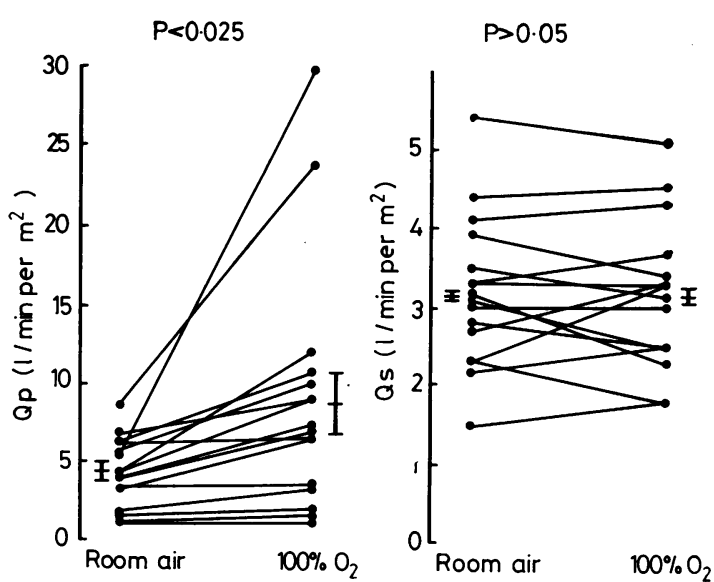

Fig. 5 The response of pulmonary and systemic blood flows to breathing oxygen. The bars represent the means and their standard errors.

calculated pulmonary vascular resistance fell in all except 1 case, and this result is highly significant $(P<0.001)$ (Fig. 6). There was no significant change in left atrial pressure during oxygen administration. Pulmonary venous $\mathrm{Po}_{2}$ rose to a mean of $332.6 \mathrm{mmHg}$. There was considerable individual variation, however, the range being $200 \mathrm{mmHg}$ to $467 \mathrm{mmHg}$.

The numerical change in pulmonary vascular resistance was closely correlated with the magnitude of the original pulmonary vascular resistance in air $(P<0.01)$ (Fig. 7).

$$
P<0.001
$$

$P>0.05$
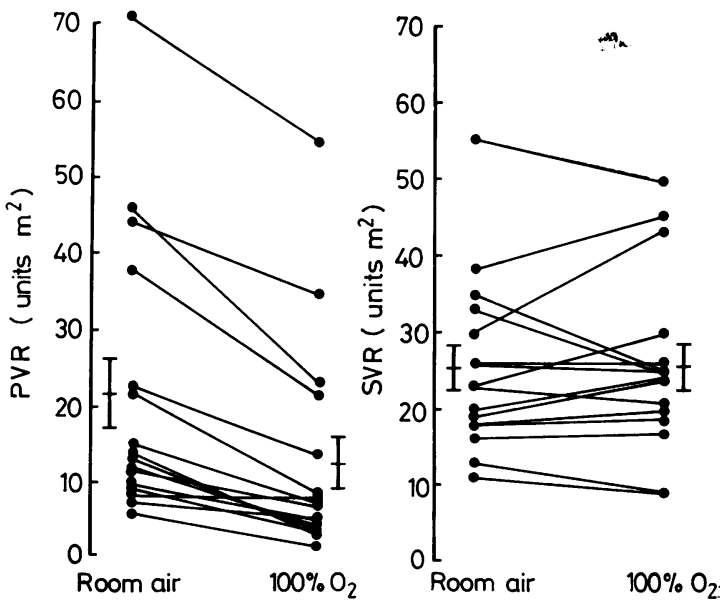

Fig. 6 The response of the pulmonary and systemic vascular resistance to oxygen. The bars represent means and their standard errors. 


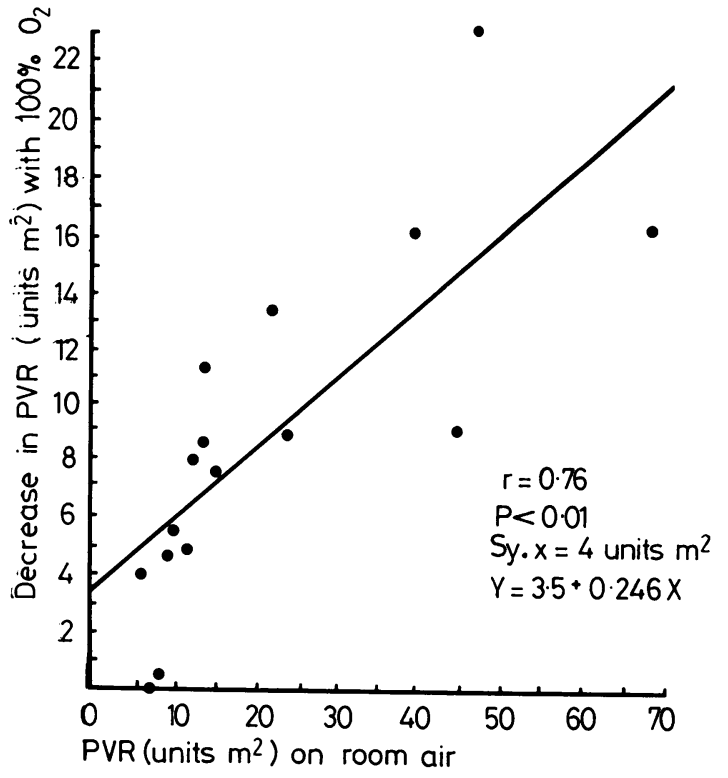

Fig. 7 The relation between the decrease in pulmonary vascular resistance induced by breathing oxygen, and the original level of pulmonary vascular resistance.

We have seen that systemic vascular resistance increased with increasing pulmonary vascular resistance in Section I of these results. On exposure to 100 per cent oxygen there was no significant change in the mean systemic arterial pressure

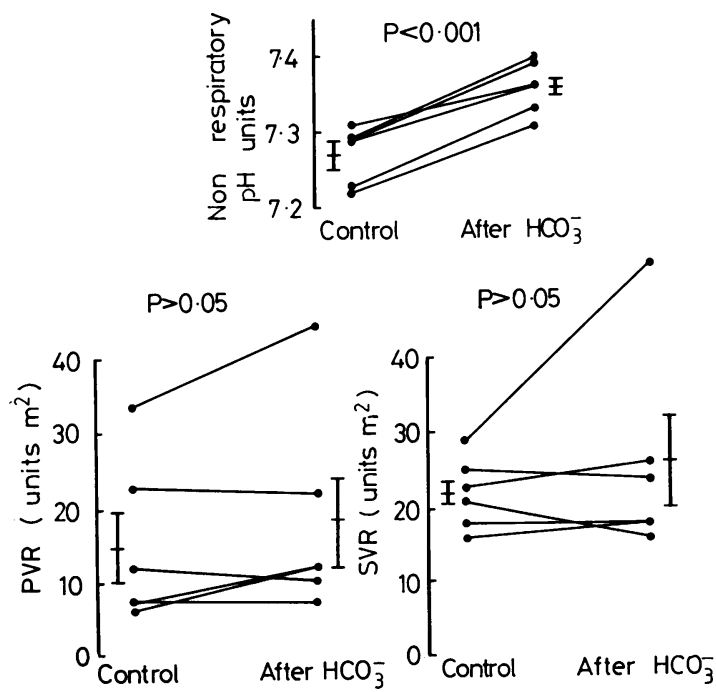

Fig. 8 The response of pulmonary and systemic vascular resistances to correction of metabolic acidosis by means of intravenous infusion of sodium bicarbonate. The bars :indicate means and their standard errors.
(Fig. 4), systemic blood flow (Fig. 5), or systemic vascular resistance (Fig. 6). The most striking effect of breathing oxygen on the mean systemic arterial pressure was to widen the range of values found (Fig. 4). The response could not be correlated, in direction or magnitude, with the age of the patient, the resting systemic arterial oxygen saturation, or the resting pulmonary vascular resistance. Because pulmonary vascular resistance changed independently of systemic vascular resistance in 100 per cent oxygen, there was a significant decrease in the ratio PVR/SVR in 100 per cent oxygen $(P<0.001)$.

\section{(III) ADMINISTRATION OF BICARBONATE}

The results in 6 subjects are reported (Fig. 8). The mean non-respiratory $p \mathrm{H}$ in these subjects was 7.26 initially, and 7.36 after administration of bicarbonate. This rise is statistically significant $(\mathrm{P}<0.001)$. The mean requirement of bicarbonate was $1.8 \mathrm{mmol} / \mathrm{kg}$ (range 0.9 to $3.3 \mathrm{mmol} / \mathrm{kg}$ ).

On administration of bicarbonate to correct metabolic acidosis there was no significant change in the mean pulmonary artery pressure, pulmonary blood flow, or pulmonary vascular resistance. Similarly, there was no statistically significant change in the mean systemic arterial pressure, blood flow, or resistance, and no change in the mean left atrial pressure. There was no corrclation between change in pulmonary vascular resistance and the original pulmonary vascular resistance, ratio of PVR/SVR, or change in non-respiratory $p H$. There was no significant change in $\mathrm{PCO}_{2}$ during bicarbonate infusion. One interesting result did emerge from the bicarbonate experiments.

When the changes in pulmonary vascular resistance experienced by the 6 subjects who had bicarbonate infusions were compared with the responses of the same 6 subjects during oxygen administration a positive linear correlation was observed $(P<0.05)$. This suggests that pulmonary arterioles which react to one stimulus are likely to react to others.

\section{(IV) HYPERVENTILATION}

The results of 4 subjects were observed. Little change in pulmonary vascular resistance was produced, and though systemic vascular resistance rose in 3 patients and remained static in the fourth, this change did not achieve statistical significance.

(V) FATE of PATIENTS STUdied

Surgery was attempted in 5 patients, in only 1 of whom was the outcome satisfactory. The details of these and the fate of the other patients are summarised in the Table. 
Of the 10 patients considered to be inoperable, 8 remain alive after a mean follow-up time of 4 years. The 2 patients who died had severely raised pulmonary vascular resistance.

\section{Discussion}

\section{EFFECT OF INTERVENTION ON PULMONARY VASCULAR BED}

With the developments of cardiac surgery in the late 1950's and early 1960's it became apparent that there was a group of patients in whom the risks of surgery were high and in whom the results were poor. These patients were characterised by extreme elevation of the pulmonary resistance, and high right heart and pulmonary artery pressures, associated with only small left-to-right, bidirectional, or reversed cardiac shunts.

The importance of a rise in the pulmonary vascular resistance in congenital heart disease was recognised by Moschowitz in 1927. The classical situation was recognised in large interventricular septal defects, forming one aspect of the natural history of this cardiac anomaly (Fyler et al., 1958; Wood, 1958; Clarkson et al., 1968). A rise in the pulmonary vascular resistance is now well recognised as a potential complication of any large left-to-right cardiac shunt or concordant transposition of the great arteries.

Whereas severe increases in pulmonary vascular resistance are rare in atrial septal defect below the age of 20 years (Swan et al., 1959) and rare in ventricular septal defect below the age of 2 years (Kidd et al., 1965), they are common in patients with transposition of the great arteries even within the first year of life (Newfeld et al., 1974; Lakier et al., 1975; Clarkson et al., 1976).

Ever since the studies of Harris (1956) and Wood et al. (1956) using acetylcholine it has been hoped that administration of oxygen or pulmonary vasodilators will distinguish between 'fixed' and 'reactive' pulmonary hypertension. Heath and Edwards (1958) proposed a histological classification of pulmonary vascular changes and related the severity of these to the reversibility of pulmonary hypertension after closure of atrial and ventricular septal defects (Heath et al., 1958b). However, no convincing correlation between response to 100 per cent oxygen and histological changes has been established (Heath et al., 1958a). In this study total pulmonary resistance tended to be higher in patients with grade 4 to 6 disease whether they were breathing room air or 100 per cent oxygen. Swan and colleagues (1959) reported that in patients undergoing closure of pulmonary hypertensive atrial septal defect, survival was much better if pulmonary vascular resistance breathing oxygen fell below 80 per cent of the resistance breathing room air. However, the ratio of total pulmonary to systemic resistance breathing room air predicted survival just as well, and no correlation between response to oxygen and histological changes in the pulmonary vessels could be established.

Though in 3 of our most severely pulmonary hypertensive patients, mean pulmonary artery pressure rose on administering oxygen, in the majority it fell. In every single patient, pulmonary blood flow rose, and pulmonary vascular resistance fell at least 20 per cent in every patient except one whose resistance on room air was relatively mildly raised at $8 \cdot 2$ units $/ \mathrm{m}^{2}$ and remained unchanged on 100 per cent oxygen. Thus, in our experience even severely raised pulmonary vascular resistance remains responsive to administration of oxygen. While it is true that others have reported patients in whom there was no apparent response to 100 per cent oxygen (Swan et al., 1959; Marshall et al., 1961 ; Krongrad et al., 1973), it should be noted that the present study is the only one concerning shunts at ventricular or great arterial level in which the left atrial and pulmonary venous oxygen saturations and pressures were directly measured. The indirect left atrial pressure is particularly unreliable in the presence of pulmonary vascular disease (Shepherd and Wood, 1959). Furthermore, during breathing of 100 per cent oxygen, the quantity of dissolved oxygen in the plasma assumes great importance in calculation of pulmonary flow by the Fick method. We found, as have others (Eggers et al., 1962), that pulmonary venous $\mathrm{Po}_{2}$ and therefore plasma dissolved oxygen was variable while breathing 100 per cent oxygen in the manner described, and therefore wonder about the wisdom of assuming that plasma dissolved oxygen is constant (Marshall et al., 1961; Krongrad et al., 1973). We did assume that no changes in oxygen consumption occurred during breathing 100 per cent oxygen, as found by Barratt-Boyes and Wood (1958) in healthy subjects. Such small increases ( 3 to $5 \%$ ) as were detected in patients with congential heart disease (Swan et al., 1959; Marshall et al., 1961) would only have served to accentuate the drop in pulmonary vascular resistance, had they been allowed for.

This fall in pulmonary vascular resistance took place without any significant change in left atrial pressure. To a considerable extent, the total fall was predictable from the control value breathing room air. The higher the control value the greater the fall on breathing 100 per cent oxygen. We conclude that testing these patients with 100 per cent oxygen provided only slightly more information about the state of the pulmonary vascular bed than did 
measuring pulmonary vascular resistance on room air. If patients exist who have severe pulmonary vascular disease which is completely unresponsive to breathing 100 per cent oxygen, it seems likely that the pulmonary vascular resistance while breathing room air would be so high as to rule out operation in any case.

Although acidosis is known to cause pulmonary arteriolar constriction (Bergofsky et al., 1962) and is thought to contribute to pulmonary arteriolar obstruction in patients with pulmonary vascular disease (Rudolph, 1966), there have been no reports of the response of the pulmonary circulation to correction of acidosis in pulmonary vascular disease.

Similarly, there have been no reports of the effects of altered $\mathrm{PCO}_{2}$ as produced by voluntary hyperventilation, on the pulmonary resistance, though a single report in 1960 (Fishman et al.) indicated that an increase in inspired $\mathrm{PCO}_{2}$ does not alter the pulmonary resistance if the ventilation is uncontrolled.

Since no consistent response to either of these interventions was obtained, it is unlikely that they are of any value in selecting patients for operation. It is of some interest that those patients who showed the greatest rise of pulmonary vascular resistance after administration of sodium bicarbonate to correct metabolic acidosis subsequently showed the greatest fall in pulmonary vascular resistance on breathing 100 per cent oxygen.

\section{EFFECT OF INTERVENTIONS ON SYSTEMIC VASCULAR BED}

Barratt-Boyes and Wood (1958) found that administration of 100 per cent oxygen in normal adult subjects resulted in a small but significant rise in systemic arterial mean pressure. Stroke index also rose significantly, but there was no overall change in cardiac index or systemic vascular resistance. In 1962 the rise in pressure was confirmed by two groups independently, but these workers also found that there was a significant rise in systemic vascular resistance, together with a rate related fall in cardiac output (Daly and Bondurant, 1962; Eggers et al., 1962). The latter group found that these effects persisted for at least 40 minutes after oxygen was discontinued. The rise in systemic vascular resistance was confirmed in patients with congenital heart disease in several studies (Swan et al., 1959; Marshall et al., 1961; Krongrad et al., 1973). However, Marshall and colleagues commented that this rise only occurred in patients under 12 years old. The younger patients in their report were studied under rectal tribromoethanol anaesthesia rather than sedation.
In the present study, rises and falls in systemic arterial mean pressure, blood flow, and resistance were found on breathing 100 per cent oxygen, and there was no significant overall change.

This variability of response was not explicable on the basis of age, systemic arterial oxygen saturation, or pulmonary vascular resistance. For this reason it seems unlikely that the variance with other reports can be explained on the basis of patient selection. In the same laboratory, using the same methods, systemic vascular resistance was found to rise significantly on administration of 100 per cent oxygen to patients with pulmonary atresia and ventricular septal defect (Macartney et al., 1973). There is one possibly important difference between the present study and all the previous studies, which is that metabolic acidosis was corrected before administration of 100 per cent oxygen. Since tissue acidosis secondary to local hypoxia is an important cause of systemic vasodilatation, it is possible that some of the observed effects of 100 per cent oxygen have been the result of reduction of local hypoxia and therefore acidosis rather than of any direct effect. This might explain the persistent response found by Eggers et al. (1962) and the age-related response found by Marshall et al. (1961) (see above). Correction of the metabolic acidosis before giving oxygen would then diminish the vasoconstriction occurring with oxygen. However, though there was overall a rise in systemic vascular resistance on correcting metabolic acidosis, this did not achieve statistical significance.

Krongrad et al. (1973) in their study of patients with ventricular septal defect and truncus arteriosus stated that, 'the single most important change on breathing oxygen was the increase in systemic resistance'. While it is true that some of our patients had a lower pulmonary vascular resistance than theirs, the groups were broadly comparable, and our findings are at variance with this conclusion. The effect on pulmonary vascular resistance was far more striking and consistent than that on systemic vascular resistance.

RELATION OF PULMONARY TO SYSTEMIC VASCULAR RESISTANCE

The term 'resistance ratio' as used in the literature can refer either to the ratio of total pulmonary to systemic resistance (Swan et al., 1959; Kirklin and DuShane, 1963; Kirklin, 1965; Cartmill et al., 1966; Hallidie-Smith et al., 1969; Krongrad et al., 1973 ) or to the ratio between pulmonary and systemic vascular resistance, as is used here. In the context of pulmonary vascular obstructive disease without obstruction to pulmonary venous return, these differ very little, since both atrial mean pres- 
sures are very low compared with mean pulmonary and systemic arterial pressures. The use of resistance ratios has distinct advantages, since errors in oxygen capacity cancel out, oxygen uptake need not be measured, and indexing of flows and resistances, which has many theoretical and practical disadvantages (Morrison and Macartney, 1978) is made unnecessary. However, this study also highlights the shortcomings of resistance ratios.

Pulmonary vascular obstructive disease is progressive. Therefore any indirect measurement of its severity should be positively correlated with the age of the patients. In this study, pulmonary artery mean pressure and vascular resistance were so correlated, but the resistance ratio was not. Thus, though the resistance ratio may be helpful in acyanotic patients when pulmonary vascular disease is mild to moderate (Kirklin, 1965; Cartmill et al., 1966), it probably is a poor measure of pulmonary vascular disease when this is severe. The reasons for this are complex. First, as previously indicated (Krongrad et al., 1973) and shown in this study, systemic and pulmonary vascular resistance are positively correlated one with the other. On the other hand, chronic systemic hypoxia in congenital heart disease has recently been shown to result in a fall in systemic vascular resistance (Morrison and Macartney, 1978). Krongrad et al. (1973) found values of indexed systemic vascular resistance in their patients with pulmonary vascular disease considerably above their normal range, using an assumed oxygen uptake. The values of absolute systemic vascular resistance in the group of patients studied here, using a measured oxygen uptake, were not significantly different from the predicted normal value for patients with congenital heart disease, when the effects of body size, arterial oxygen saturation, premedication, and haematocrit were allowed for by stepwise regression analysis (Morrison and Macartney, 1978). Thus our results indicate no specific, direct, correlation between pulmonary and systemic vascular resistance. The correlation between the two may be simply the result of haematocrit, a rise in which increases resistance in both the systemic and pulmonary vascular beds. On the other hand, our group of patients had a somewhat lower mean systemic arterial oxygen saturation than that described by Krongrad et al. (1973), so that the effects of pulmonary vascular resistance and systemic arterial oxygen saturation in the systemic vascular bed in our group may have cancelled each other out. It should also be noted that comparisons between groups of patients with regard to indexed systemic vascular resistance are only valid if they are of comparable size. This is because indexing systemic vascular resistance does not completely correct for body size. As body size increases, so does indexed resistance (Morrison and Macartney, 1978).

Whatever the cause of these phenomena, it remains true that abrupt falls of systemic vascular resistance, such as occur with fevers or angiography, initiate a vicious spiral of arterial desaturation followed by further systemic vasodilatation and so on (Krongrad et al., 1973).

\section{Conclusion}

Not all the original objectives of this study were achieved, but some unexpected and interesting findings were recorded. To some extent the need for evaluation of pulmonary vascular disease has diminished with advances in surgery. It has been shown that pulmonary vascular resistance may either continue to rise or fall after closure of ventricular septal defect in patients over 2 years of age, but on average it remains unchanged. However, if operation is carried out below 2 years of age, pulmonary vascular resistance postoperatively is normal, or almost so, regardless of its preoperative level (DuShane et al., 1976). Now that primary repair of ventricular septal defect in infancy can be carried out with a low mortality (de Leval et al., 1974), pulmonary vascular disease should become as rare in ventricular septal defect as it now is in atrial septal defect and persistent ductus arteriosus. To a lesser extent, because of high risks and a greater tendency to pulmonary vascular disease, the same is true for truncus arteriosus and transposition of the great arteries.

\section{References}

Adams, P., jun, Lucas, R. V., Ferguson, D. K., and Lillehei, C. W. (1957). Significance of pulmonary vascular pathology in ventricular septal defect as determined by lung biopsy (abstract). American fournal of Diseases of Children, 94, 476.

Auld, P. A. M.. Johnson, A. L., Gibbons, J. E., and McGregor, $M$. (1963). Changes in pulmonary vascular resistance in infants and children with left-to-right intracardiac shunts. Circulation, 27, 257-260.

Barratt-Boyes, B. G., and Wood, E. H. (1958). Cardiac output and related measurements and pressure values in the right heart and associated vessels, together with an analysis of the hemodynamic responses to the inhalation of high oxygen mixtures in healthy subiects. Fournal of Laboratory and Clinical Medicine, 51, 72-90.

Bergofsky, E. H. Lehr, P. E., and Fishman, A. P. (1962). The effect of changes in hydrogen ion concentration on the pulmonary circulation. Fournal of Clinical Investigation, 41, 1492-1502.

Blount, S. G., jun, and Woodwark, G. M. (1960). Considerations involved in the selection for surgery of patients with ventricular septal defects. American fournal of Cardiology, 5, 223-233. 
Cartmill, T. B., DuShane, J. W., McGoon, D. C., and Kirklin, J. W. (1966). Results of repair of ventricular septal defect. Fournal of Thoracic and Cardiovascular Surgery, 52, 486-499.

Clarkson, P. M., Frye, R. L., DuShane, J. W., Burchell, H. B., Wood, E. H., and Weidman, W. H. (1968). Prognosis for patients with ventricular septal defect and severe pulmonary vascular obstructive disease. Circulation, 38, 129-135.

Clarkson, P. M., Neutze, J. M., Wardill, J. C., and BarrattBoyes, B. G. (1976). The pulmonary vascular bed in patients with complete transposition of the great arteries. Circulation, 53, 539-543.

Daly, W. J., and Bondurant, S. (1962). Effects of oxygen breathing on the heart rate, blood pressure and cardiac index of normal men-resting, with reactive hyperemia, and after atropine. Fournal of Clinical Investigation, 41, 126-132.

de Leval, M., Taylor, J. F. N., and Stark, J. (1974). Primary repair of ventricular septal defect in infancy (abstract). British Heart Fournal, 36, 400.

DuShane, J. W., Krongrad, E., Ritter, D. G., and McGoon, D. C. (1976). The fate of raised pulmonary vascular resistance after surgery in ventricular septal defect. In The Child with Congenital Heart Disease after Surgery, pp. 299-312. ed, B. S. L. Kidd and R. D. Rowe. Futura, New York.

Eggers, G. W. N., jun, Paley, H. W., Leonard, T. J., and Warren, J. V. (1962). Hemodynamic responses to oxygen breathing in man. Fournal of Applied Physiology, 17, 75-82.

Fishman, A. P., Fritts, H. W., jun, and Cournand, A. (1960). Effects of breathing carbon dioxide upon the pulmonary circulation. Circulation, 22, 220-225.

Flamm, M. D., Cohn, K. E., and Hancock, E. W. (1969). Measurement of systemic cardiac output at rest and exercise in patients with atrial septal defect. American fournal of Cardiology, 23, 258-265.

Fyler, D. C., Rudolph, A. M., Wittenborg, M. H., and Nadas, A. S. (1958). Ventricular septal defect in infants and children. A correlation of clinical, physiologic and autopsy data. Circulation, 18, 833-851.

Goodwin, J. F. (1961). Ventricular septal defect. Proceedings of the Royal Society of Medicine, 54, 783-785.

Gotsman, M. S., Beck, W., Barnard, C. N., and Schrire, V. (1969). Haemodynamic studies after repair of ventricular septal defect. British Heart fournal, 31, 63-71.

Hallidie-Smith, K. A. (1968). The long-term results of closure of ventricular septal defect with pulmonary vascular disease. American Heart fournal, 76, 591-595.

Hallidie-Smith, K. A., Hollman, A., Cleland, W. P., Bentall, H. H., and Goodwin, J. F. (1969). Effects of surgical closure of ventricular septal defects upon pulmonary vascular disease. British Heart Fournal, 31, 246-260.

Hallman, G. L., Cooley, D. A., Wolfe, R. R., and McNamara, D. G. (1964). Surgical treatment of ventricular septal defect associated with pulmonary hypertension. Fournal of Thoracic and Cardiovascular Surgery, 48, 588-600.

Harris, P. (1956). Influence of acetylcholine on the pulmonary arterial pressure. British Heart fournal, 19, 272-278.

Heath, D., and Edwards, J. E. (1958). The pathology of hypertensive pulmonary vascular disease. A description of six grades of structural changes in the pulmonary artery with special reference to congenital cardiac septal defects. Circulation, 18, 533-547.

Heath, D., Helmholz, H. F., jun, Burchell, H. B., DuShane, J. W., and Edwards, J. E. (1958a). Graded pulmonary vascular changes in cases of atrial and ventricular septal defect and patent ductus arteriosus. Circulation, 18, 1155-1166.

Heath, D., Helmholz, H. F., Burchell, H. B., DuShane, J. W., Kirklin, J. W., and Edwards, J. E. (1958b). Relationship between structural changes in the small pulmonary arteries and the immediate reversibility of pulmonary hypertension following closure of ventricular and atrial septal defects. Circulation, 18, 1167-1174.

Kappagoda, C. T., Greenwood, P., Macartney, F. J., and Linden, R. J. (1973). Oxygen consumption of children with congenital diseases of the heart. Clinical Science and Molecular Medicine, 45, 107-114.

Kappagoda, C. T., Linden, R. J., and Snow, H. M. (1970). An approach to the problems of acid-base balance. Clinical Science, 39, 169-182.

Kappagoda, C. T., Stoker, J. B., Snow, H. M., and Linden, R. J. (1972). The $\mathrm{CO}_{2}$ titration curve of mixed venous blood. Clinical Science, 43, 553-559.

Kidd, L., Rose, V., Collins, G., and Keith, J. (1965). The hemodynamics in ventricular septal defect in childhood. American Heart fournal, 70, 732-738.

Kimball, K. G., and McIlroy, M. B. (1966). Pulmonary hypertension in patients with congenital heart disease. American Fournal of Medicine, 41, 883-897.

Kirklin, J. W. (1965). Ventricular septal defect with pulmonary vascular disease. New Zealand Medical fournal, 64 (Cardiac Suppl.), 34-36.

Kirklin, J. W., and DuShane, J. W. (1963). Indications for repair of ventricular septal defects. American fournal of Cardiology, 12, 75-79.

Krongrad, E., Helmholz, H., jun, and Ritter, D. G. (1973). Effect of breathing oxygen in patients with severe pulmonary vascular obstructive disease. Circulation, 47, 94-100.

Lakier, J. B., Stanger, P., Heymann, M. A., Hoffman, J. I. E., and Rudolph, A. M. (1975). Early onset of pulmonary vascular obstruction in patients with aortopulmonary transposition and intact ventricular septum. Circulation, 51, 875-880.

McKenzie, S. A., MacArthur, C. G. E., Godfrey, S., and Hallidie-Smith, K. A. (1977). Hypertensive pulmonary vascular disease in children. Detection by radioactive nitrogen $\left({ }^{13} \mathrm{~N}\right)$ inhalation and injection. British Heart fournal, 39, 866-871.

Macartney, F. J., Deverall, P. B., and Scott, O. (1973). The haemodynamic characteristics of systemic arterial blood supply to the lungs. British Heart fournal, 35, 28-37.

Mair, D. D., Ritter, D. G., Danielson, G. K., Wallace, R. B., and McGoon, D. C. (1976). The palliative Mustard operation; rationale and results. American fournal of Cardiology, 37, 762-768.

Mair, D. D., Ritter, D. G., Davis, G. D., Wallace, R. B., Danielson, G. K., and McGoon, D. C. (1974). Selection of patients with truncus arteriosus for surgical correction. Anatomic and hemodynamic considerations. Circulation, 49, 144-151.

Marshall, H. W., Swan, H. J. C., Burchell, H. B., and Wood, E. H. (1961). Effect of breathing oxygen on pulmonary artery pressure and pulmonary vascular resistance ir patients with ventricular septal defect. Circulation, 23, 241-252.

Miller, H. C., Brown, D. J., and Miller, G. A. H. (1974). Comparison of formulae used to estimate oxygen saturation of mixed venous blood from caval samples. British Heart fournal, 36, 446-451.

Morrison, G. W., and Macartney, F. J. (1978). The determinants of systemic vascular resistance during cardiac catheterisation. Submitted for publication.

Morrison, G. W., Scott, O., and Macartney, F. J. (1977). Retrograde left atrial catheterisation in children with congenital heart disease. American Heart fournal, 94, 333-335.

Moschowitz, E. (1927). Hypertension of the pulmonary circulation. Its causes, dynamics and relation to other circulatory states. American fournal of the Medical Sciences, 174, 388-406. 
Newfeld, E. A., Paul, M. H., Muster, A. J., and Idriss, F. S. (1974). Pulmonary vascular disease in complete transposition of the great arteries. A study of 200 patients. American Fournal of Cardiology, 34, 75-82.

Reeve, R., Selzer, A., Popper, R. W., Leeds, R. F., and Gerbode, F. (1966). Reversibility of pulmonary hypertension following cardiac surgery. Circulation, 33 and 34, Suppl. I, 107-114.

Rudolph, A. M. (1966). Biochemical and haemodynamic aspects of cyanosis. In The Heart and Circulation in Newborn Infants, p. 173. Grune and Stratton, New York.

Shepherd, J. T., and Wood, E. H. (1959). The role of vessel tone in pulmonary hypertension. Circulation, 19, 641-645.

Slonim, N. B., Bell, B. P., and Christensen, S. E. (1967). Cardiopulmonary Laboratory Basic Methods and Calculations: A Manual of Cardiopulmonary Technology. Thomas, Springfield, Illinois.

Swan, H. J. C., Burchell, H. B., and Wood, E. H. (1959).
Effect of oxygen on pulmonary vascular resistance in patients with pulmonary hypertension associated with atrial septal defect. Circulation, 20, 66-73.

Wagenvoort, C. A., Nauta, J., van der Schaar, P. J., Weeda, H. W. H., and Wagenvoort, N. (1967). Effect of flow and pressure on pulmonary vessels. Circulation, 35, 1028-1037.

Wood, P. (1958). The Eisenmenger syndrome of pulmonary hypertension with reversed central shunt. British Medical Fournal, 2, 701-709; 755-762.

Wood, P., Besterman, E. M., Towers, M. K., and McIlroy, M. B. (1956). The effect of acetylcholine on pulmonary vascular resistance and left atrial pressure in mitral stenosis. British Heart Fournal, 19, 279-286.

Requests for reprints to Dr G. W. Morrison, Department of Cardiovascular Studies, The University, Leeds LS2 9JJ. 